\title{
The FSHR Expression in Head and Neck Squamous Cell Cancer. A Pilot Immunohistochemical Study
}

\author{
TOMAS OLEJAR ${ }^{1,2}$, DAVID VETVICKA ${ }^{1}$, JAN BOUCEK $^{3}$, MICHAL ZABRODSKY ${ }^{3}$, \\ JIRI BENES ${ }^{1}$, MARTINA KABESOVA ${ }^{1}$ and PAVLA POUCKOVA ${ }^{1}$ \\ ${ }^{1}$ Institute of Biophysics and Informatics, 1 st Faculty of Medicine, Charles University, Prague, Czech Republic; \\ ${ }_{2}^{2}$ Institute of Pathology and Molecular Medicine, Thomayer Memorial Hospital in Prague and 3rd Faculty of Medicine, \\ Charles University, Prague, Czech Republic; \\ ${ }^{3}$ Department of Otorhinolaryngology Head and Neck Surgery, First Faculty of Medicine, \\ Charles University and University Hospital Motol, Prague, Czech Republic
}

\begin{abstract}
Background/Aim: Follicle-stimulating hormone receptor (FSHr), expressed on endothelial cells of vessels in different malignant tumors, has been recently investigated as a potential pan-receptor of cancer treatment. However, the expression of this receptor has also been confirmed in other tissues under pathological conditions including cancer. The aim of the presented pilot study was to evaluate the expression of FSHr in head and neck squamous cancer (HNSCC). Patients and Methods: A total of 28 HNSCC patient samples were immunohistochemically analyzed for the presence of FSHr using a commercially available primary antibody. Results: FSHr was detected not only in the tumor tissue, but also in the basal layer or dysplastic parts of squamous mucosa and also in fibroblasts surrounding the tumor tissue. Conclusion: FSHr is present on different benign or malignant mesenchymal and epithelial structures in HNSCC. A brief literature review revealed a wider role of FSHr in the development of neoplasia.
\end{abstract}

Follicle-stimulating hormone (FSH) is a gonadotropin secreted by the anterior pituitary gland in both, males and females. The main function of FSH is to regulate the growth, maturation, and reproductive processes of the body through the FSH receptor (FSHr) on granulosa cells of ovarian follicles in females and on Sertolli cells in the testes of males, respectively $(1,2)$. On the other hand, genetic and pharmacologic FSH suppression prevents loss of bone mass

Correspondence to: David Vetvicka, Institute of Biophysics and Informatics, $1^{\text {st }}$ Faculty of Medicine, Charles University, Salmovska 1, Prague 120 00, Czech Republic. Tel: +420 224965801, e-mail: david.vetvicka@lf1.cuni.cz

Key Words: FSHr, HNSCC, neoangiogenesis, histopathology, immunohistochemistry. and reduces body fat suggesting its potential role in the treatment of obesity and osteoporosis $(3,4)$. Currently, FSHr is considered an anticancer treatment due to its presence on the endothelium of cancer-associated vessels (5). It is present on certain solid tumor cells including ovarian, prostate and thyroid cancer $(6,7)$.

The role of FSHr in cancer is not clear and further research is needed. However, a relationship with the vascular endothelial growth factor (VEGF) signaling has been reported: Activated $\mathrm{Gq} / 11$ protein induces VEGF receptor signaling, even in the absence of VEGF and signaling through the FSHr can lead to the activation of $\mathrm{Gq} / 11$ protein (8). Migration and proliferation of endothelial cells can be thus enhanced by FSH-FSHr signaling without the need of VEGF. Additionally, in ovarian granulosa cells FSH signaling through its receptor leads to VEGF upregulation by increasing the levels of hypoxia-inducible factor- $1 \alpha$ protein under normoxic conditions (9). FSHr may thus promote the neoangiogenesis, through the induction of VEGF signaling pathway. As VEGF is a negative prognostic factor in head and neck cancer (10), the potential FSHr expression may be of interest as yet another prognostic marker.

FSHr can also be considered a target for nano-based probes for fluorescence-guided surgery in head and neck squamous cell cancer (11). The first step is to examine, immunohistochemically, the presence of FSHr in samples of confirmed head and neck squamous cell cancer using commercially available antibodies.

\section{Patients and Methods}

Subjects. A total of 28 patients were enrolled into the study. They were all patients of the Department of ENT (Ear, Nose and Throat) and Head and Neck Surgery, Teaching Hospital in Motol, Prague, Czech Republic. All of them underwent head and neck surgery for squamous cell cancer. Detailed characteristics of patients are 
Table I. Characterization of the subjects evaluated in the study.

\begin{tabular}{|c|c|c|c|c|}
\hline Surgery type & $\begin{array}{c}\text { Subsequent } \\
\text { treatment }\end{array}$ & $\begin{array}{l}\text { Primary } \\
\text { location }\end{array}$ & $\begin{array}{c}\text { TNM } \\
\text { classification }\end{array}$ & $\begin{array}{l}\text { Grade of } \\
\text { squamous } \\
\text { cell cancer }\end{array}$ \\
\hline $\begin{array}{l}\text { Total laryngectomy, lateral pharyngectomy and resection } \\
\text { of the base of tongue, neck dissection bilateral }\end{array}$ & RT & $\begin{array}{l}\text { Larynx, pharynx, } \\
\text { base of tongue }\end{array}$ & $\mathrm{pT} 2 \mathrm{pN} 2 \mathrm{~b}$ & 2 \\
\hline Total laryngectomy, neck dissection, right side & NA & Larynx & pT2 pN1 & 3 \\
\hline $\begin{array}{l}\text { Lateral pharyngotomy, resection of the base of tongue, } \\
\text { neck dissection bilateral }\end{array}$ & CHRT & Base of tongue & $\mathrm{pT} 3 \mathrm{pN} 2 \mathrm{c}$ & 3 \\
\hline Total laryngectomy, neck dissection, left side & NA & Larynx & урT2 урN0* & 2 \\
\hline Total laryngectomy, neck dissection bilateral & RT & Larynx & pT3 pN1 & 2 \\
\hline Total laryngectomy, neck dissection, right side & CHRT & Larynx & pT4a pN0 & 1 \\
\hline Total laryngectomy, neck dissection, right side & CHRT & Larynx & pT4a pN2a & 3 \\
\hline Total laryngectomy, neck dissection, left side & NA & Larynx & pT3 pN1 & 3 \\
\hline Total laryngectomy, neck dissection, right side & NA & Larynx & & 3 \\
\hline Total laryngectomy, neck dissection, right side & NA & Larynx & pT4a pN2b & 3 \\
\hline Transmandibular buccopharyngectomy, neck dissection, left side & RT & Tonsil & pT2 N1 & 2 \\
\hline $\begin{array}{l}\text { Lateral pharyngotomy, resection of the base of tongue, } \\
\text { and neck dissection, left side }\end{array}$ & NA & Base of tongue & pT2 pN0 & 2 \\
\hline Transmandibular buccopharyngectomy, neck dissection, left side & NA & Tonsil & pT2 pN0 & 3 \\
\hline $\begin{array}{l}\text { Lateral pharyngotomy, resection of the base of tongue, } \\
\text { neck dissection, left side }\end{array}$ & CHRT & Base of tongue & pT4a pN2a & 2 \\
\hline Lateral pharyngotomy, resection of the tumor, neck dissection, left side & NA & Tonsil & $\mathrm{pT} 2 \mathrm{pN} 2 \mathrm{~b}$ & 3 \\
\hline Trans oral resection, neck dissection, right side & RT & Tonsil & $\mathrm{pT} 1 \mathrm{pN} 2 \mathrm{~b}$ & 2 \\
\hline $\begin{array}{l}\text { Lateral pharyngotomy, resection of the base of tongue, } \\
\text { neck dissection, right side }\end{array}$ & NA & Base of tongue & $\mathrm{pT} 1 \mathrm{pN} 1$ & 2 \\
\hline Trans oral resection, neck dissection, left side & CHRT & Tonsil & $\mathrm{pT} 2 \mathrm{pN} 2 \mathrm{~b}$ & 2 \\
\hline Lateral pharyngotomy, resection of tumor, neck dissection, bilateral & CHRT & Tonsil & pT3 pN2c & 3 \\
\hline Total laryngectomy, neck dissection, right side & NA & Supraglottic & pT4a pN1 & 2 \\
\hline Transmandibular buccopharyngectomy, neck dissection, left side & CHRT & Tonsil & pT2 pN1 & 2 \\
\hline $\begin{array}{l}\text { Combined approach: transoral resection, lateral pharyngotomy, } \\
\text { resection of the tumor, neck dissection, right side }\end{array}$ & None & Tonsil & $\mathrm{pT} 2 \mathrm{pN} 2 \mathrm{~b}$ & 2 \\
\hline Total laryngectomy, neck dissection, bilateral & RT & Larynx & pT4a pN0 & 2 \\
\hline $\begin{array}{l}\text { Lateral pharyngotomy, resection of the base of tongue, } \\
\text { neck dissection, right side }\end{array}$ & $\mathrm{RT}$ & Base of tongue & $\mathrm{pT} 2 \mathrm{pN} 2 \mathrm{~b}$ & 2 \\
\hline Trans oral resection, neck dissection, right side & NA & Tonsil & pT2 pN0 & 2 \\
\hline Total laryngectomy, neck dissection, bilateral & NA & Larynx & pT3 pN2b & 3 \\
\hline $\begin{array}{l}\text { Combined approach: transoral resection, lateral pharyngotomy, } \\
\text { resection of the tumor, neck dissection, right side }\end{array}$ & NA & Oropharynx & $\mathrm{pT} 2 \mathrm{pN} 2 \mathrm{~b}$ & 2 \\
\hline Transmandibular buccopharyngectomy, neck dissection, right side & NA & Tonsil & pT4a pN2b & 2 \\
\hline
\end{tabular}

RT: Radiotherapy; CHRT: chemoradiotherapy; NA: not applicable; *only one subject received neoadjuvant chemotherapy.

summarized in Table I. All patients signed informed consent before entering the study and the study protocol was approved by the Central Ethics Committee of Teaching Hospital Motol, Prague, Czech Republic (Approval No. MZVES201624062015). In addition, all data were analyzed while respecting patient privacy.

In vivo tumor model. A human ovarian carcinoma cell line OVCAR3 was purchased from ATCC (HTB-161). Before application, cells were cultivated in RPMI-1640 medium supplemented with $10 \%$ fetal bovine serum, $2 \%$ penicillin/streptomycin, $1.25 \%$ L-glutamine, and $1 \%$ sodium pyruvate. The tumors were grown in the immunodeficient athymic nude CD-1 strain mice (obtained from Velaz, Ltd., Prague, Czech Republic). A total of 6, 8-weeks old, females were inoculated subcutaneously to the right flank region with a mixture of $5 \times 10^{6}$ OVCAR-3 cells and Matrigel (1:2). When the tumor reached on average of $7 \mathrm{~mm}$ in diameter, mice were sacrificed and tumor samples were collected for further immunohistochemical analysis. The animals were kept in an air laminar flow box for small laboratory animals under aseptic conditions with radiation-sterilized bedding SAWI Research Bedding (Jelu-Werk, Ltd., Rosenberg, Germany), were fed sterile Ssniff diet (Ssniff Spezialdiaeten, Ltd., Soest, Germany) and had unlimited access to autoclaved water. All mice were treated in accordance with the Act on Experimental Work with Animals (Decrees No. 311/97; 117/87 and Act No. 246/96) of the Czech Republic, which is fully compatible with the corresponding European Union directives.

Histology. Formalin-fixed and paraffin-embedded slices, 5-mm thick, from tumor samples were routinely stained with hematoxylin and eosin for confirmation of the clinical diagnosis. 
Immunocytochemistry. Microscopic tissue slices, 5-mm thick, were deparaffinized, rehydrated, and pretreated with a citrate buffer $(\mathrm{pH}$ 7.6) for $15 \mathrm{~min}$ in a microwave oven. Nonspecific signal was blocked by incubating with bovine serum albumin in PBS (150 $\mathrm{ml} / 10 \mathrm{ml}$ ) for $30 \mathrm{~min}$. Primary antibodies against the following antigens were used: 1) Follicle-stimulating hormone receptor (1:400, rabbit polyclonal, ab113421, ABCAM, Cambridge, UK); 2) Cytokeratin AE1/AE3 (1:50, mouse monoclonal, M351501, DAKO, Santa Clara, CA, USA). The slices were then incubated overnight at $4^{\circ} \mathrm{C}$. Detection of immunostaining was carried out using secondary antibodies conjugated with Alexa Fluor 488 (1:1000, goat anti-rabbit, H+L IgG, Thermo Fischer Scientific, Rockford, IL, USA) and Alexa Fluor 680 (1:1000, goat anti-mouse, H+L IgG, Thermo Fischer Scientific). Slides incubated only with the secondary antibody were used as specificity controls. DAPI (VECTASHIELD ${ }^{\circledR}$ Mounting Medium with DAPI, Vector Laboratories Ltd., Peterborough, UK) was used to stain the nucleus.

Microscopy. Leica TCS SP5 confocal fluorescent laser scanning microscope (Leica Microsystems Inc., Wetzlar, Germany) was used with a $40 \times$ objective (a pinhole of 1 Airy unit). Alexa 488conjugated antibody was excited at $488 \mathrm{~nm}$ with a $20-\mathrm{mW}$ argon laser, whereas Alexa-680-conjugated antibody was excited at 633 $\mathrm{nm}$ with a $1.2-\mathrm{mW}$ HeNe laser.

Statistical analysis. Student's $t$-test was performed to evaluate statistical significance between groups. $p<0.05$ was considered as a minimal level of significance. All statistical analysis was performed with SPSS software.

\section{Results}

Presence of FSHr in positive control. Presence of FSHr was demonstrated in different ovarian cancer cell lines including OVCAR-3, SKOV-3 and OVCAR-4 (12). OVCAR-3 cell line was selected to test anti-FSHr primary antibody as a positive control and immunohistochemical positivity was confirmed in this tumor transplanted into nude CD1 mice (Figure 1).

Presence of FSHr in the interstitium. Presence of FSHr was recorded on a number of cells in the interstitium. In different areas including submucosa bellow the normal or dysplastic squamous epithelium and in the tumor stroma, FSHr positivity was recorded on the stromal spindle shaped cells with processes, probably fibroblasts with different intensity in submucosa, near small vessels and glands (Figure 2). It seems, that stronger positivity of fibroblasts can be observed in regions with dysplastic mucosa and in tumor associated fibroblasts than in fibroblasts underlying normal mucosa without dysplasia in squamous epithelial layer (Figure 3). In the tumor stroma, FSHr positivity was also recorded on the stromal spindle shaped cells with processes, the tumor associated fibrolasts (Figure 4a, b).

Presence of FSHr in squamous epithelium of mucosa. FSHr positivity was identified only on the stem cells in the single basal row adjacent to the basement membrane of the common squamous epithelium. On the other hand, in dysplastic epithelium, spreading of FSHr positivity into higher cell layers was observed (Figure 3). The anti-FSHr antibody and thus, the detection of FSHr itself visualizes dysplastic elements in the squamous mucosa spreading into superficial mucosa layers of the ENT region.

Presence of FSHr in tumor tissue. In total, 28 samples of well, moderately and poorly differentiated head and neck cancers were investigated for FSHr positivity. In the tumors, different presence of FSHr was recorded: Zero and individual positive cancer elements were observed in some cases of the squamous head and neck cancer, however, in majority grouped positive cells and zonal and/or diffuse positivity of the tumor masses. It also seems that in some cases, certain degree of polarization of the positivity can be observed and it seems that FSHr positivity can, similarly to the observation in normal and dysplastic mucosa, see above, distinguish proliferating structures from differentiated ones (Figure 4). Generally, 0 to individual FSHr positive cells were observed in 3 samples (approx. 11\%), 1-25\% FSHr positivity was observed in 6 samples (approx. 21\%), 25-0\% positivity was observed in 10 samples (approx. 36\%) and 50$100 \%$ positivity was observed in 9 samples (approx. 32\%). The relationship between the percentage of FSHr positivity and histopathology tumor grade is presented in Figure 5 and does not show any significant difference (Grade II vs. Grade III $p=0.12$, Grade I sample was not big enough to be statistically analyzed).

\section{Discussion}

In our study, FSHr positivity was detected in cancer cells, tumor-associated fibroblasts, but also in dysplastic portions of squamous epithelium and/or in the basal layer of common squamous mucosa. FSHr expression in the tumor mass, as detected by immunohistochemistry, varied case by case and did not show any correlation with the histopathology grading.

Despite the fact that the role of FSHr expressed on endothelial cells of vessels in different malignant tumors is recently investigated as a potential pan-receptor of cancer treatment (13), the presence of this receptor directly on the cancer cell is not surprising. Expression of FSHr was observed in malignant cells and to a lesser degree in benign thyroid tumors as well as in the walls of blood vessels, but was not limited only to the endothelium (14). FSHr was also located on glandular and stromal cells of normal prostate, benign prostate hyperplasia and samples of prostate cancer. Treatment of the PC3 prostate cancer cell line with FSH resulted in increased production of cAMP (15) and FSH levels are also considered as the prostate cancer predictor 

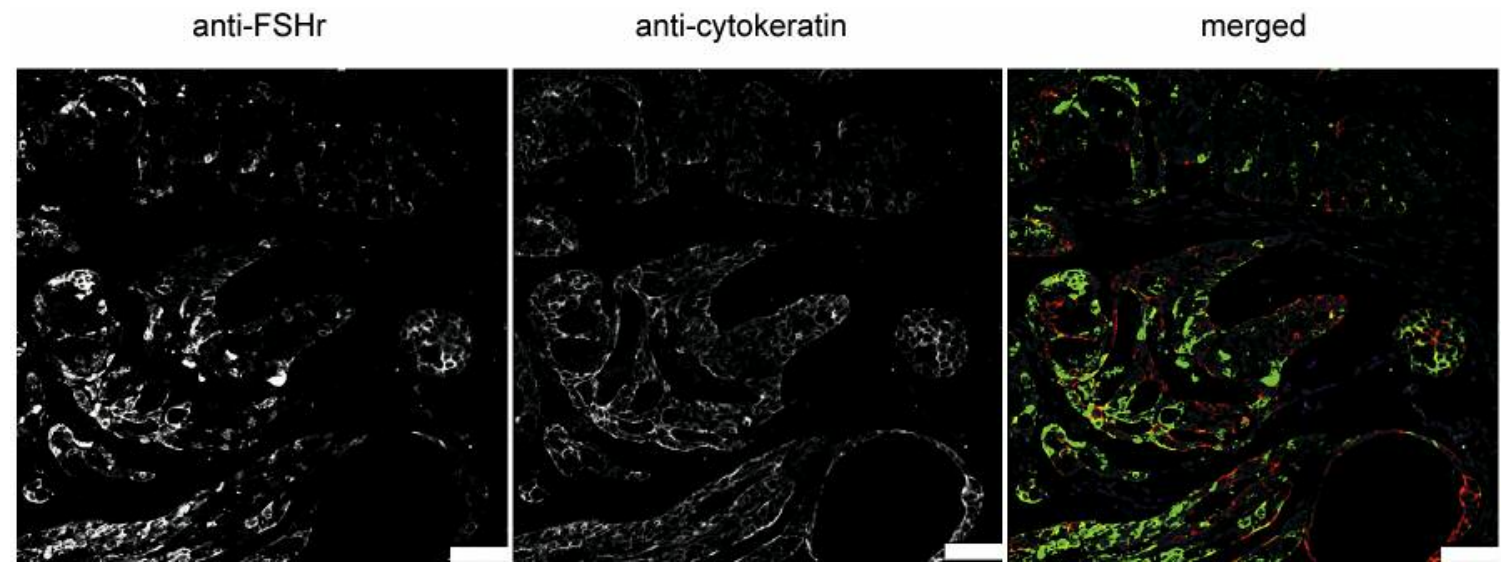

Figure 1. Positive control of FSHr: FSHr positivity (green immunofluorescence) in tumor growing from OVCAR-3 cells transplanted into nu/nu mouse. FSHr - green (primary anti FSHR antibody, dilution 1:400, secondary antibody conjugated with Alexa 488, 1:1000), cytokeratin - red (primary anti cytokeratin AE1/AE3 antibody, dilution 1:50, secondary antibody conjugated with Alexa 680, dilution 1:1000), DAPI-blue. Scale bars indicate $75 \mu \mathrm{m}$.
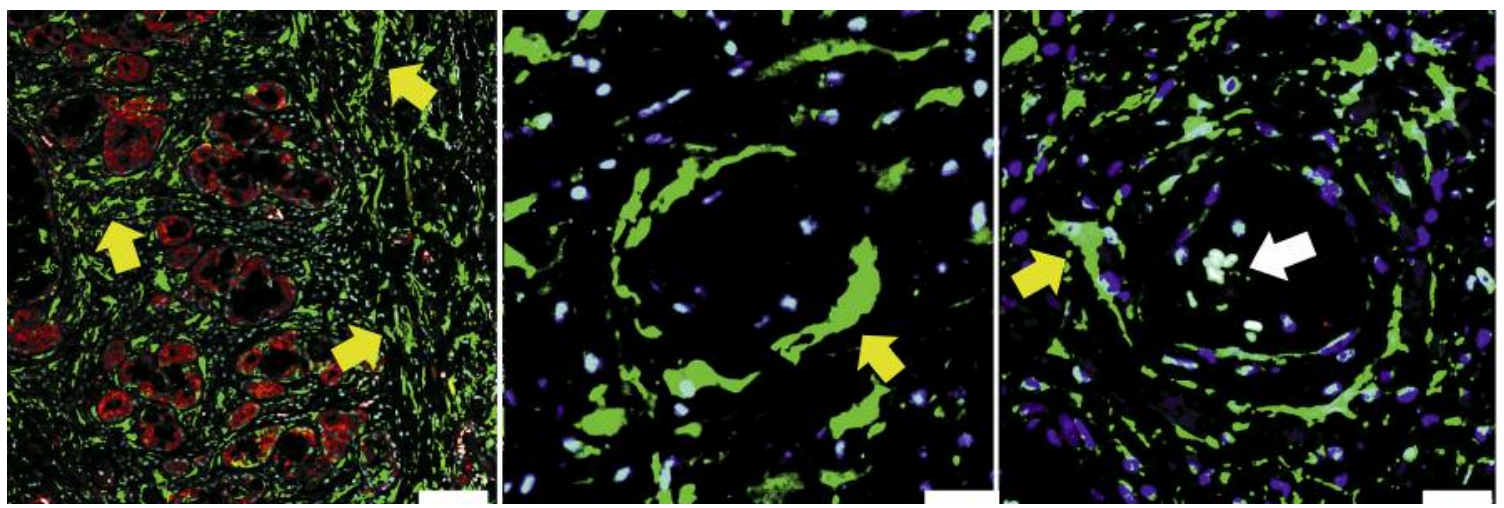

Figure 2. FSHr positivity in non-tumor fibroblasts in the interstitium. Positive fibroblasts were observed freely distributed in the interstitium as well as in circumscribing small vessels (yellow arrows). Autofluorescence of erythrocytes (white arrow) as well as of elastic membranes was also observed. $\mathrm{FSHr}$ - green (primary anti FSHR antibody, dilution 1:400, secondary antibody conjugated with Alexa 488, dilution 1:1000), sections were counterstained for nuclei with DAPI - blue. Cumulative autofluorescence of erythrocytes can be seen as white color. Scale bars indicate 25 um.

(16). FSHr belongs also to molecules expressed in pancreatic tumors and thus, its role in tumor growth, apoptosis, angiogenesis and metastasis is expected (17). Increased FSH serum levels may contribute to the progression of breast cancer (18). Functional FSHr is expressed also on the rhabdomyosarcoma cells where it participates in the pathogenesis and progression of the disease (19). Expression of FSHr has been shown in ovarian cancer tissues (20) where the receptor inhibits apoptosis of cancer cells (21) and FSH levels in ascites is considered as an independent factor predicting patient's survival (22). The presence of FSHr in cancer tissues and especially in the endothelium has been reviewed by Bonci et al. (23).
Among nonmalignant diseases, FSHr expression was observed in the epithelium of biliary cysts of subjects with autosomal dominant polycystic kidney disease (24). FSHr expression is enhanced in rat cholangiocytes and hepatocytes after the bile duct ligation (25).

FSHr is also expressed on mesenchymal cells. In mouse embryonic fibroblasts, FSH probably promotes signaling of bone morphogenetic protein 9 through an $\mathrm{FSH} / \mathrm{FSHr}$ (FSHr)/cAMP dependent pathway (26). On the other hand, FSH stimulates bone resorption by osteoclasts and negatively regulates osteoblasts number. This effect is mediated by FSHr present on mesenchymal stem cells (27). However, immunohistochemical specificity $v s$. sensitivity of primary 
a
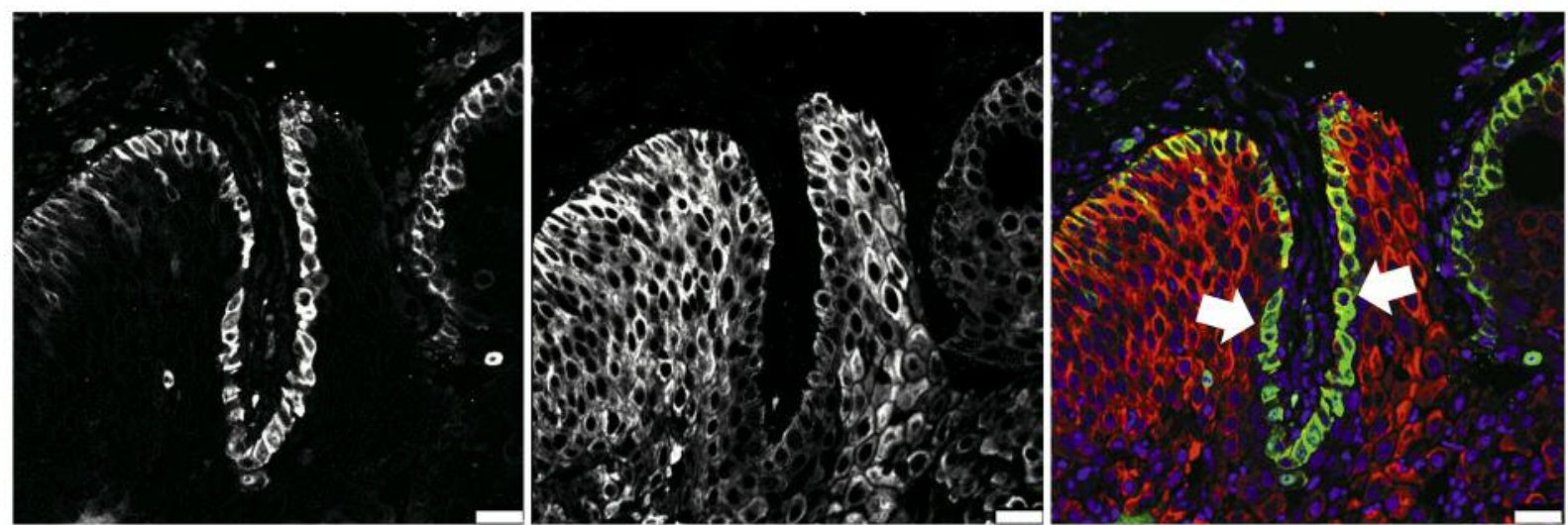

b
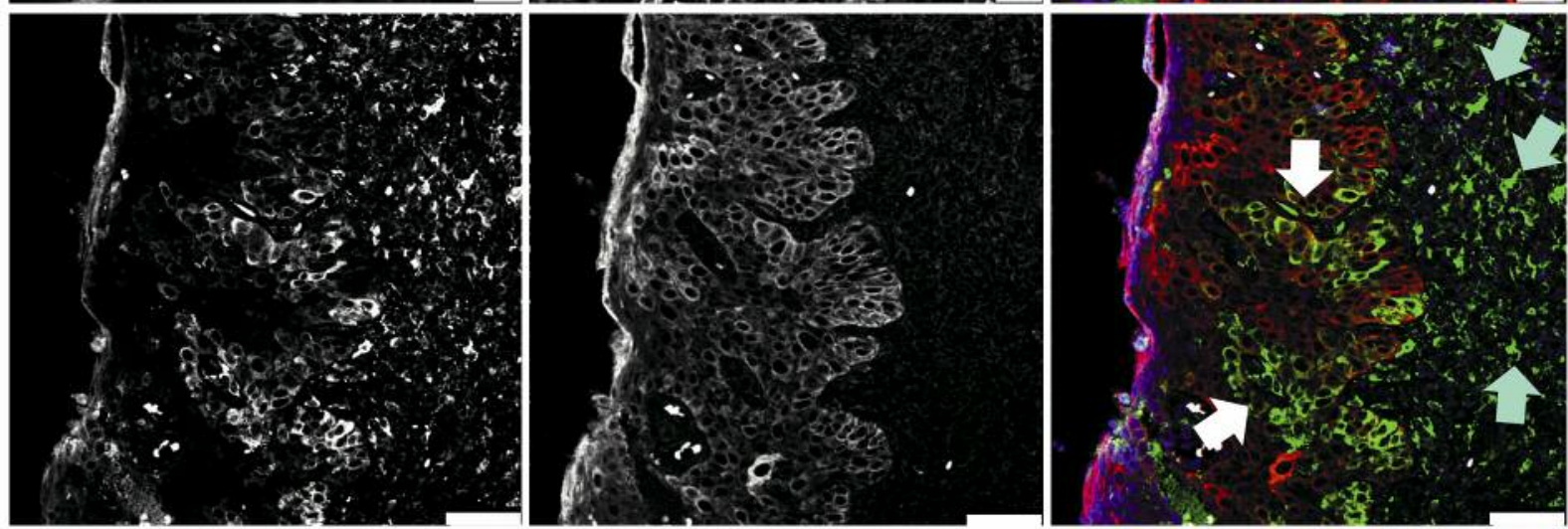

C
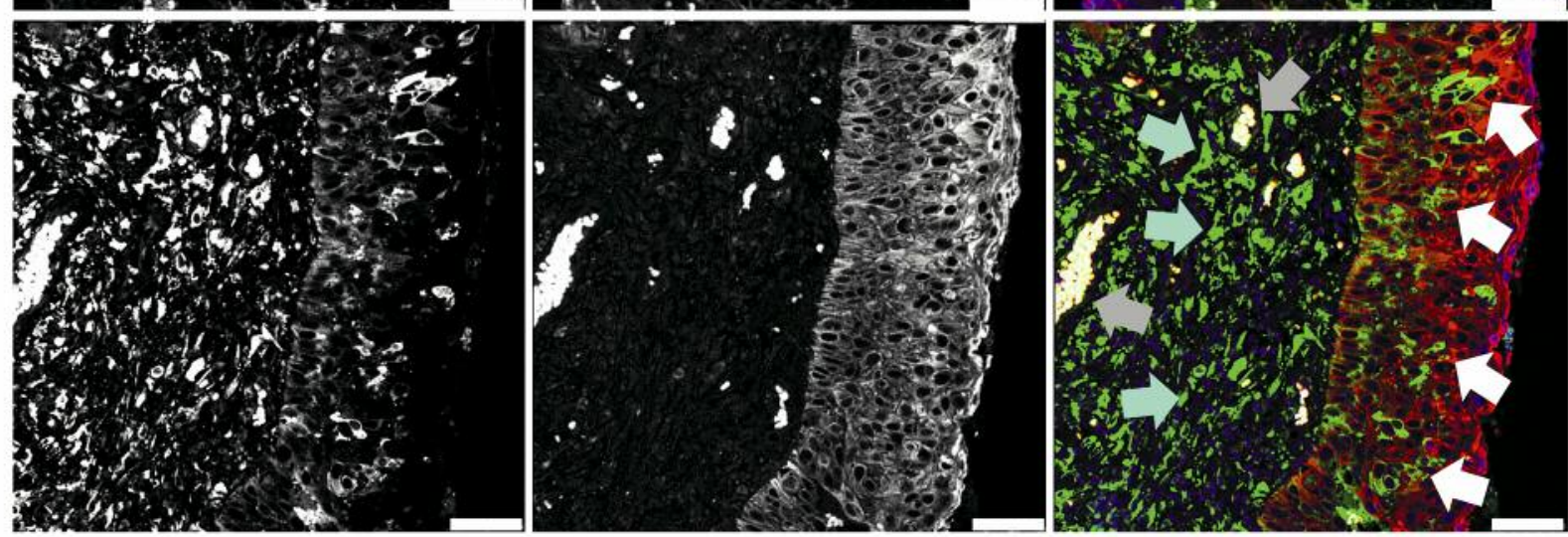

Figure 3. FSHr positivity in normal and reactiveldysplastic squamous mucosa. In normal mucosa (a), only a single basal layer was positive for $\mathrm{FSHr}$ (white arrows). Reactive/dysplastic ( $b$ and $c$ ) changes in mucosa are accompanied by re-distribution of FSHr expression also to upper layers of epithelium (white arrows). Observe also enhanced FSHr positivity in submucosal fibroblasts related to the reactiveldysplastic epithelium (blue arrows). FSHr - green (primary anti FSHR antibody, dilution 1:400, secondary antibody conjugated with Alexa 488, 1:1000), cytokeratin - red (primary anti cytokeratin AE1/AE3 antibody, dilution 1:50, secondary antibody conjugated with Alexa 680, dilution 1:1000), DAPI - blue. Cumulative autofluorescence of erythrocytes can be seen as the white color (grey arrows). Scale bars indicate $25 \mu \mathrm{m}(a)$ and $50 \mu \mathrm{m}(b, c)$.

antibodies detecting FSHr either on cancer or supportive tissue must be always considered (28).

Immunohistochemical positivity of FSHr on the normal basal layer of squamous mucosa that is spreading to the suprabasal layers in reactive and/or dysplastic changes is suggesting the role of this receptor in the regulation of the cell proliferation. Our findings are in agreement with those obtained using Proliferating cell nuclear antigen (PCNA) as 
anti-cytokeratin

anti-FSHr

merged

a
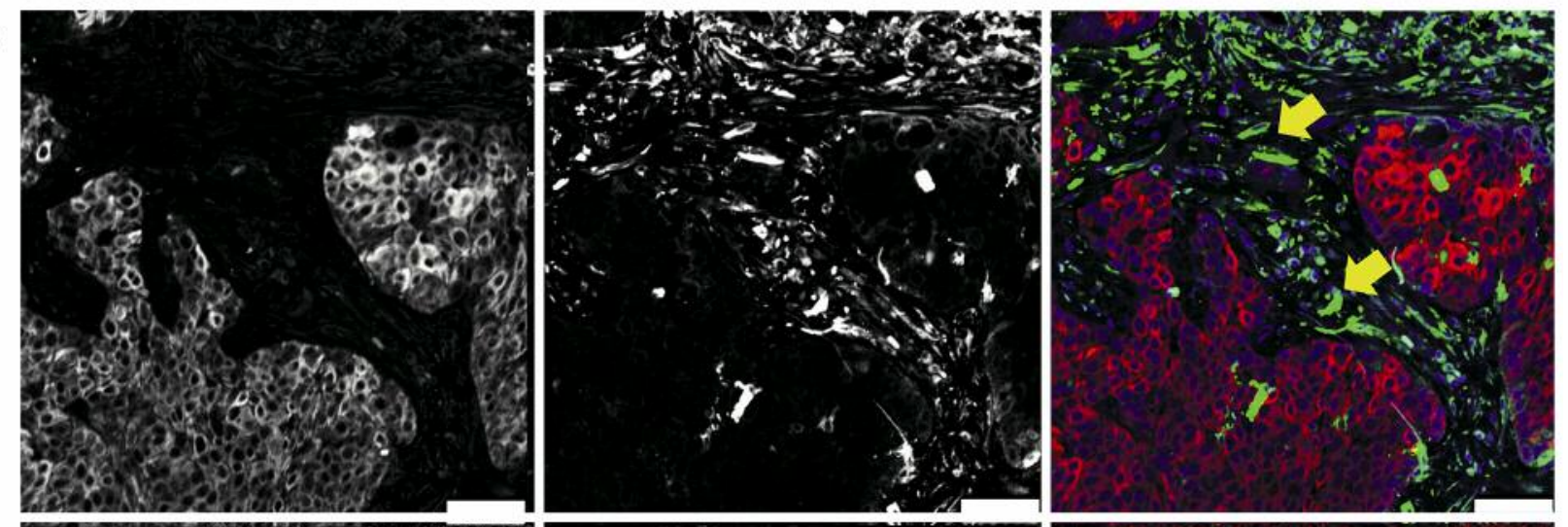

b

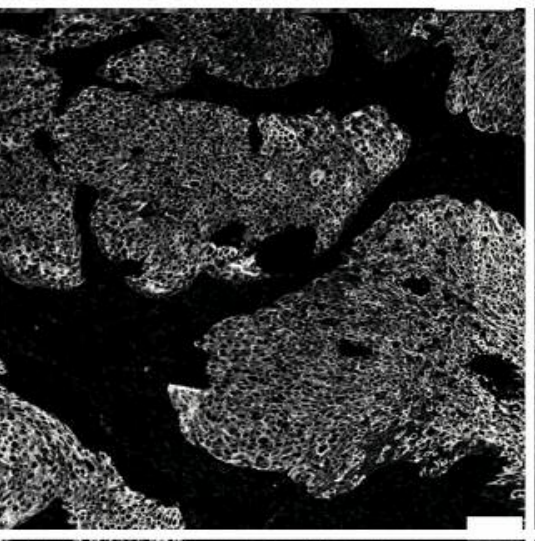

C
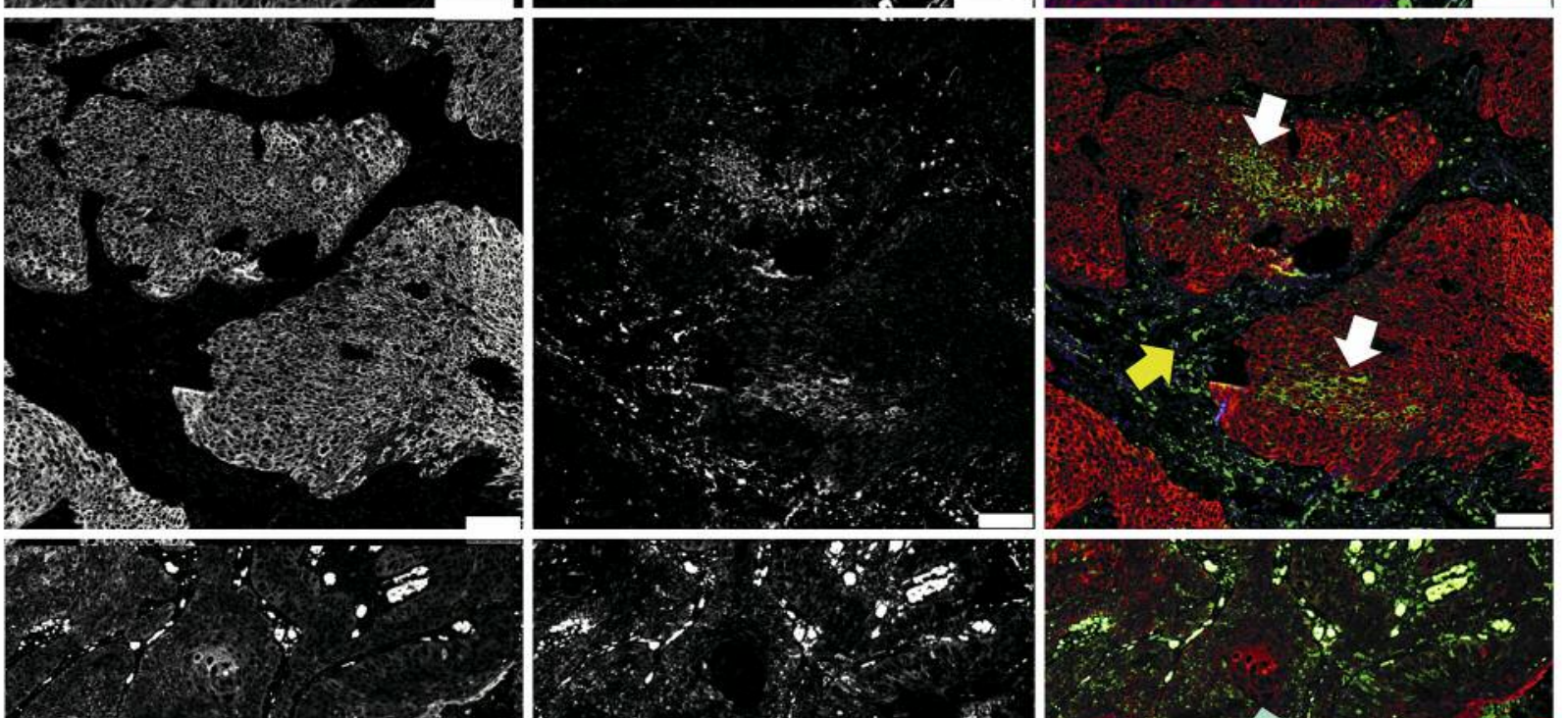

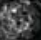

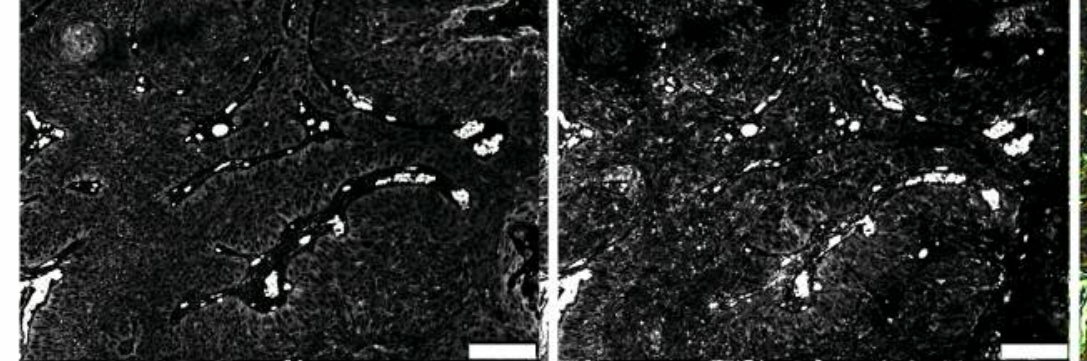

d
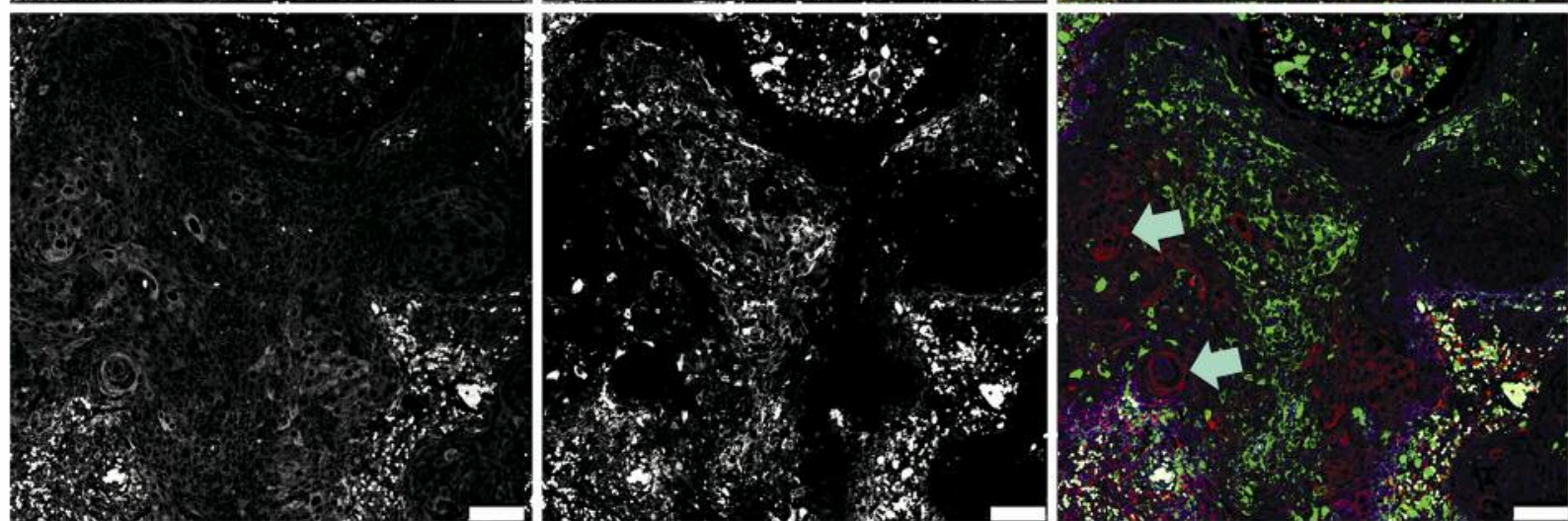
a possible marker for dysplasia of the upper aerodigestive tract $(29,30)$. Taken together with our results of polarized and "laminar" FSHr positivity in samples of HNSCC, the possible role of FSHr in proliferation and regulation of cancer cells warrants further investigation.

\section{Conclusion}

Revealing the presence of FSHr on proliferating nonmalignant, pre-malignant or malignant epithelial and tumorassociated mesenchymal components of HNSCC supports a potential wider role of this receptor in the development and progression of this malignancy. Based on this study, the potential role of FSHr as a target for fluorescence-guided surgery in HNSCC remains disputable due to the FSHr presence on non-malignant structures including normal squamous mucosa.

\section{Conflicts of Interest}

All Authors declare no conflicts of interest.

\section{Authors' Contributions}

TO performed histology and immunihistochemistry and confocal imaging, DV and MK performed in vitro studies, JB and MZ collected the clinical tumor samples, JB analysed the data, PP planned the experiments. TO and DV wrote the manuscript, MK and PP edited the manuscript. All Authors discussed the results and gave feedback on the manuscript.

\section{Acknowledgements}

The Authors acknowledge the Institute of Medical Biochemistry and Laboratory Diagnostics, First Faculty of Medicine, Charles University and General University Hospital in Prague for their support with the confocal imaging. This work was supported by the Ministry of Health of the Czech Republic (grant no. 16-28594A).

Figure 4. FSHr positivity in tumor tissue varies. In poorly differentiated HNSCC areas, FSHr expression varies from zero (a) to only a few grouped cells in the center of cancer epithelial cords (b) (white arrows). FSHr positivity in tumor associated fibroblasts can be also observed (yellow arrows). In differentiated HNSCC areas ( $c$ and d), FSHr positivity comprised proliferating parts resembling basal and spinal layers of squamous mucosa while keratinizing cells remain $\mathrm{FSHr}$ negative (blue arrows). FSHr - green (primary anti FSHR antibody, dilution 1:400, secondary antibody conjugated with Alexa 488, dilution 1:1000), cytokeratin - red (primary anti cytokeratin AE1/AE3 antibody, dilution 1:50, secondary antibody conjugated with Alexa 680, dilution 1:1000), DAPI - blue. Cumulative autofluorescence of erythrocytes can be observed as the white color. Scale bars indicate $50 \mu \mathrm{m}(a), 75 \mu \mathrm{m}$ (b), $100 \mu \mathrm{m}(c)$ and $75 \mu \mathrm{m}(\mathrm{d})$.

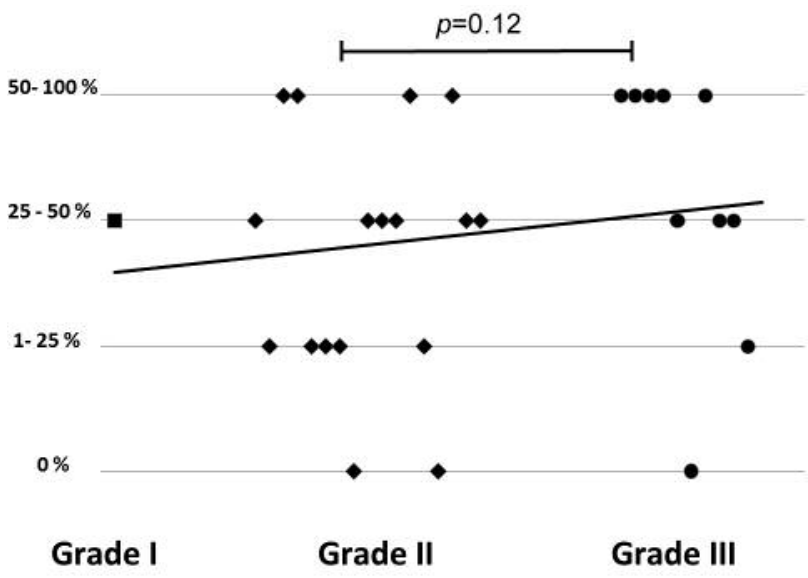

Figure 5. Relationship between the percentage of FSHr positivity and histopathology tumor grade does not show any significant difference (Grade II vs. Grade III, $p=0.12$ ).

\section{References}

1 Plant TM and Marshall GR: The functional significance of FSH in spermatogenesis and the control of its secretion in male primates. Endocr Rev 22: 764-786, 2001. PMID: 11739331. DOI: 10.1210/edrv.22.6.0446

2 Macklon NS and Fauser BC: Follicle development during the normal menstrual cycle. Maturitas 30: 181-188, 1998. PMID: 9871911. DOI: 10.1016/s0378-5122(98)00072-3

3 Zaidi M, New MI, Blair HC, Zallone A, Baliram R, Davies TF, Cardozo C, Iqbal J, Sun L, Rosen CJ and Yuen T: Actions of pituitary hormones beyond traditional targets. J Endocrinol 237(3): R83-R98, 2018. PMID: 29555849. DOI: 10.1530/JOE17-0680

4 Sun L, Peng Y, Sharrow AC, Iqbal J, Zhang Z, Papachristou DJ, Zaidi S, Zhu LL, Yaroslavskiy BB, Zhou H, Zallone A, Sairam MR, Kumar TR, Bo W, Braun J, Cardoso-Landa L, Schaffler MB, Moonga BS, Blair HC and Zaidi M: FSH directly regulates bone mass. Cell 125(2): 247-260, 2006. PMID: 16630814. DOI: 10.1016/j.cell.2006.01.051

5 Radu A, Pichon C and Camparo P: Expression of folliclestimulating hormone receptor in tumor blood vessels. N Engl J Med 363: 1621-1630, 2010. PMID: 20961245. DOI: 10.1056/ NEJMoa1001283

6 Gartrell BA, Tsao C and Galsky MD: The follicle-stimulating hormone receptor: A novel target in genitourinary malignancies. Urologiconcology 31(8): 1403-1407, 2013. PMID: 22513137. DOI: $10.1016 /$ j.urolonc.2012.03.005

7 Papadimitriou K, Kountourakis P, Kottorou AE, Antonacopoulou AG, Rolfo C, Peeters M and Kalofonos HP: Follicle-stimulating hormone receptor (FSHR): A promising tool in oncology? Mol Diagn Ther 20(6): 523-530, 2016. PMID: 27392476. DOI: 10.1007/s40291-016-0218-z

8 Castro-Fernández C, Maya-Núñez G and Méndez JP: Regulation of follicle-stimulating and luteinizing hormone receptor signaling by "regulator of G protein signaling" proteins. Endocrine 25: 49, 2004. PMID: 15545706. DOI: 10.1385/ENDO:25:1:49 
9 Alam H, Weck J, Maizels E, Park Y, Lee EJ, Ashcroft M and Hunzicker-Dunn M: Role of the phosphatidylinositol-3-kinase and extracellular regulated kinase pathways in the induction of hypoxia-inducible factor (HIF)-1 activity and the HIF-1 target vascular endothelial growth factor in ovarian granulosa cells in response to follicle-stimulating hormone. Endocrinology 150(2): 915-928, 2009. PMID: 18845636. DOI: 10.1210/en.2008-0850

10 Zang J, Li C, Zhao L, Shi M, Zhou Y, Wang J and Li X: Prognostic value of vascular endothelial growth factor in patients with head and neck cancer: A meta-analysis. Head Neck 35: 1507-1514, 2013. PMID: 22987573. DOI: 10.1002/hed.23156

11 Hong H, Yan Y, Shi S, Graves SA, Krasteva LK, Nickles RJ, Yang $\mathrm{M}$ and Cai W: PET of follicle-stimulating hormone receptor: broad applicability to cancer imaging. Mol Pharm 12(2): 403-410, 2015. PMID: 25581441. DOI: $10.1021 / \mathrm{mp} 500766 \mathrm{x}$

12 Gera S, Kumar S S, Swamy SN, Bhagat R, Vadaparty A, Gawari $\mathrm{R}$, Bhat R and Dighe RR: Follicle-stimulating hormone is an autocrine regulator of the ovarian cancer metastatic niche through notch signaling. J Endocr Soc 3(2): 340-357, 2018. PMID: 30680340. DOI: 10.1210/js.2018-00272

13 Siraj A, Desestret V, Antoine M, Fromont G, Huerre M, Sanson M, Camparo P, Pichon C, Planeix F and Gonin J: Expression of follicle-stimulating hormone receptor by the vascular endothelium in tumor metastases. BMC Cancer 13: 246, 2013. PMID: 23688201. DOI: 10.1186/1471-2407-13-246

14 Pawlikowski M, Jaranowska M, Pisarek H, Kubiak R, FussChmielewska J and Winczyk K: Ectopic expression of folliclestimulating hormone receptors in thyroid tumors. Arch Med Sci 11(6): 1314-1317, 2015. PMID: 26788096. DOI: 10.5114/aoms. 2015.56357

15 Mariani S, Salvatori L, Basciani S, Arizzi M, Franco G, Petrangeli E, Spera G and Gnessi L: Expression and cellular localization of follicle-stimulating hormone receptor in normal human prostate, benign prostatic hyperplasia and prostate cancer. J Urol 175(6): 2072-2077, 2006. PMID: 16697805. DOI: 10.1016/S0022-5347(06)00273-4

16 Ide H, Yasuda M, Nishio K, Saito K, Isotani S, Kamiyama Y, Muto S and Horie S: Development of a nomogram for predicting high-grade prostate cancer on biopsy: the significance of serum testosterone levels. Anticancer Res 28(4C): 2487-2492, 2008. PMID: 18751439.

17 Damaskos C, Garmpis N, Karatzas T, Kostakis ID, Nikolidakis L, Kostakis A and Kouraklis G: Nuclear receptors in pancreatic tumor cells. Anticancer Res 34(12): 6897-6911, 2014. PMID: 25503115

18 Zhou J, Chen Y, Huang Y, Long J, Wan F and Zhang S: Serum follicle-stimulating hormone level is associated with human epidermal growth factor receptor type 2 and $\mathrm{Ki} 67$ expression in post-menopausal females with breast cancer. Oncol Lett 6(4): 1128-1132, 2013. PMID: 24137476. DOI: 10.3892/ol.2013.1516

19 Poniewierska-Baran A, Schneider G, Sun W, Abdelbaset-Ismail A, Barr FG and Ratajczak MZ: Human rhabdomyosarcoma cells express functional pituitary and gonadal sex hormone receptors: Therapeutic implications. Int J Oncol 48(5): 1815-1824, 2016. PMID: 26983595. DOI: 10.3892/ijo.2016.3439

20 Perales-Puchalt A, Svoronos N, Rutkowski MR, Allegrezza MJ, Tesone AJ, Payne KK, Wickramasinghe J, Nguyen JM, O'Brien SW, Gumireddy K, Huang Q, Cadungog MG, Connolly DC, Tchou J, Curiel TJ and Conejo-Garcia JR: Follicle-stimulating hormone receptor is expressed by most ovarian cancer subtypes and is a safe and effective immunotherapeutic target. Clin Cancer Res 23(2): 441-453, 2017. PMID: 27435394. DOI: 10.1158/1078-0432.CCR-16-0492

21 Zhang Z, Zhu Y, Lai Y, Wu X, Feng Z, Yu Y, Bast RC Jr., Wan $\mathrm{X}, \mathrm{Xi} \mathrm{X}$ and Feng Y: Follicle-stimulating hormone inhibits apoptosis in ovarian cancer cells by regulating the OCT4 stem cell signaling pathway. Int J Oncol 43(4): 1194-1204, 2013. PMID: 23921511. DOI: 10.3892/ijo.2013.2054

22 Chen FC, Oskay-Ozcelik G, Bühling KJ, Köpstein U, Mentze M, Lichtenegger W and Sehouli J: Prognostic value of serum and ascites levels of estradiol, FSH, LH and prolactin in ovarian cancer. Anticancer Res 29(5): 1575-1578, 2009. PMID: 19443368.

23 Bonci EA, Irimie A, Buiga R, Cosmin Lisencu I, Iuliana Maja L and Piciu D: Follicle-stimulating hormone receptors: a new immunohistochemical marker in cancers? J BUON 22(5): 13521359, 2017. PMID: 29135125.

24 Onori P, Mancinelli R, Franchitto A, Carpino G, Renzi A, Brozzetti S, Venter J, Francis H, Glaser S, Jefferson DM, Alpini $\mathrm{G}$ and Gaudio E: Role of follicle-stimulating hormone on biliary cyst growth in autosomal dominant polycystic kidney disease. Liver Int 33(6): 914-925, 2013. PMID: 23617956. DOI: 10.1111/liv.12177

25 Mancinelli R, Onori P, Gaudio E, DeMorrow S, Franchitto A, Francis H, Glaser S, Carpino G, Venter J, Alvaro D, Kopriva S, White M, Kossie A, Savage J and Alpini G: Follicle-stimulating hormone increases cholangiocyte proliferation by an autocrine mechanism via cAMP-dependent phosphorylation of ERK1/2 and Elk-1. Am J Physiol Gastrointest Liver Physiol 297(1): G1126, 2009. PMID: 19389804. DOI: 10.1152/ajpgi.00025.2009

26 Su XY, Zou X, Chen QZ, Zeng YH, Shao Y, He BC and Liu H: Follicle-stimulating hormone $\beta$-subunit potentiates bone morphogenetic protein 9-induced osteogenic differentiation in mouse embryonic fibroblasts. J Cell Biochem 118(7): 17921802, 2017. PMID: 27996168 . DOI: $10.1002 /$ jcb.25849

27 Zhu LL, Blair H, Cao J, Yuen T, Latif R, Guo L, Tourkova IL, Li J, Davies TF, Sun L, Bian Z, Rosen C, Zallone A, New MI and Zaidi M: Blocking antibody to the $\beta$-subunit of FSH prevents bone loss by inhibiting bone resorption and stimulating bone synthesis. Proc Natl Acad Sci USA 109(36): 14574-14579, 2012. PMID: 22908268. DOI: 10.1073/pnas.1212806109

28 Bonci EA, Buiga R, Badan M, Maja LI, Gata VA, Lisencu IC, Irimie A, Achimas-Cadariu P and Piciu D: Follicle - stimulating hormone receptors: A comparison of commercially- available monoclonal and polyclonal antibodies as immunohistochemical markers for cancer research. J BUON 26(3): 1912-1921, 2018. PMID: 30610821.

29 Coltrera MD, Zarbo RJ, Sakr WA and Gown AM: Markers for dysplasia of the upper aerodigestive tract. Suprabasal expression of PCNA, p53, and CK19 in alcohol-fixed, embedded tissue. Am J Pathol 141(4): 817-825, 1992. PMID: 1384338.

30 Martínez-Lara I, González-Moles MA, Ruiz-Avila I, Bravo M, Ramos MC and Fernández-Martínez JA: Proliferating cell nuclear antigen (PCNA) as a marker of dysplasia in oral mucosa. Acta Stomatol Belg 93(1): 29-32, 1996. PMID: 8986050.

Received September 18, 2019

Revised December 1, 2019

Accepted December 2, 2019 